\title{
COMMENT
}

\section{Recommendations for improving the estimation of the number of seabirds potentially sustained by fisheries discards}

\author{
Yorgos Stratoudakis* \\ Instituto de Investigaçāo das Pescas e do Mar (IPIMAR), Avenida de Brasilia, P-1449-006 Lisboa, Portugal
}

\begin{abstract}
Seabirds feed extensively on fisheries waste (discards and offal), and quantifying the degree of utilisation is an important and politically sensitive area of research (Furness 1992, Garthe \& Hüppop 1994, Oro \& Ruiz 1997). Studies on the feeding ecology of seabirds offer insights into issues like the energy flow in marine ecosystems and the ecological impacts of fishing activities. Recently, consumption experiments have been combined with published data on fisheries discards and bird bioenergetics to estimate the number of seabirds sustained by feeding exclusively on fisheries waste (Garthe et al. 1996, Walter \& Becker 1997). Here, I point out some of the estimation problems faced in such studies and recommend ways for improving the data analysis. In particular, I demonstrate how the Delta method (Seber 1982) can provide estimates of precision, thus allowing more informed decision-making by conservation and fisheries managers.

Consumption of fisheries waste by seabirds is usually estimated by experiments conducted on board research vessels. In these experiments, items normally found in the discarded component of the commercial catch are discharged individually, and their fate is recorded. The realism of this design has been questioned for some time, mainly because experimental discarding cannot reproduce the conditions during commercial fishing (Garthe \& Huppop 1994). For example, Garthe \& Hüppop (1998) recently showed that discarding up to 50 items simultaneously resulted in significantly lower estimates of consumption rates than those obtained from single release experiments. Data from the Scottish discard sampling programme (Stratoudakis 1997. Stratoudakis et al. 1998) suggest that multiple releases are closer to commercial dis-
\end{abstract}

-E-mail: yorgos@ipimar.pt carding practices, where large quantities of fish are processed per haul (median of 1200 fish discarded per haul in the Scottish demersal fisheries).

Despite these deficiencies, the results of feeding experiments are used to quantify the total consumption of fisheries waste by seabirds in a fishery. Estimates of the number of seabirds $(N)$ potentially sustained by feeding on fisheries waste are usually obtained by:

(1) multiplying estimates of total discards (D) for a fishery by an average estimate of consumption rate $(C R)$ to get the total biomass potentially available to seabirds;

(2) multiplying this biomass by a calorific value (CAL) to obtain an energetic equivalent;

(3) multiplying the energetic equivalent by the assimilation efficiency $(A E)$ to get the potentially utilised part of this food source; and

(4) dividing the potentially utilised energy by the average annual energetic requirement $(E R)$ of a typical bird in the studied community:

$$
N=(D \times C R \times C A L \times A E) / E R
$$

Estimation is usually performed separately for groups of fishery waste assumed to have similar calorific values and consumption rates (roundfish, flatfish, etc.), while spatial variation in discards may also be taken into account (Garthe et al. 1996).

An issue often ignored in seabird studies that use the above estimation protocol is that the precision of $N$ (which depends on the precision of the estimated input variables) should also be estimated. Reliable discard data are difficult to collect and annual estimates of total discards are usually based on small and variable samples. For example, annual estimates of biomass for the main commercial gadoids discarded by Scottish demersal vessels in the North Sea and the West of Scotland have coefficients of variation around 30 to 
$40 \%$ (Stratoudakis et al. unpubl.), although the Scottish discards sampling programme is among the most extensive applied worldwide. Published estimates of the remaining parameters suggest similar elements of systematic and random variation. The calorific value of fish that form prey of seabirds in the North Sea varies between seasons and fish lengths (Hislop et al. 1991) Pooling estimates of calorific values across several years give coefficients of variation (CVs) of 5 to $10 \%$ at length, which roughly translate to 15 to $20 \%$ when length stratification is also ignored. Consumption rates vary among areas, seasons, and type and size of discarded material (Garthe et al. 1996, Garthe \& Hüppop 1998). Using arcsine transformations of the consumption rates tabulated in Garthe et al. (1996), I roughly estimated CVs of 10 to $20 \%$ for roundfish and 35 to $40 \%$ for flatfish. Furness (1978) used simulated data to estimate CVs close to $30 \%$ for the annual energetic requirements of 2 of the most abundant seabirds in the Shetland area.

When estimating a variable as a function of several input variables, analytic variance estimation may be difficult or impossible. In such cases, the Delta method (Seber 1982) can offer an approximate numerical solution by means of a Taylor expansion (e.g. Prager \& MacCall 1988, Borchers et al. 1997). In the case of Eq. (1), where the output variable is a simple product (or quotient) of uncorrelated input variables, the Delta method reduces the coefficient of variation $(\mathrm{CV})$ of the estimated number of seabirds to:

$$
\begin{aligned}
\mathrm{CV}^{2}(N)= & \mathrm{CV}^{2}(D)+\mathrm{CV}^{2}(C R)+\mathrm{CV}^{2}(C A L)+ \\
& \mathrm{CV}^{2}(A E)+\mathrm{CV}^{2}(E R)
\end{aligned}
$$

In a hypothetical example, I consider CVs of 30 to $40 \%$ for the total discards, 20 to $30 \%$ for consumption rate, 15 to $20 \%$ for calorific values and 25 to $35 \%$ for annual energetic requirements. Assimilation efficiency generally varies less than the remaining parameters (ICES 1994), and was therefore assumed to be measured without error. Under this scenario, CV for the estimated number of seabirds ranges between 46 and $64 \%$.

The above approximate estimate of CV demonstrates that the currently available point estimates of the number of seabirds potentially sustained by fisheries waste should only be seen as order of magnitude indicators. For example, Walter \& Becker (1997) estimated that approximately 60000 seabirds could be sustained for a year by exclusively feeding on the waste produced by beam trawlers targeting brown shrimp Crangon crangon off Lower Saxony, Germany. Similarly, Garthe et al. (1996) estimated that the entire North Sea fisheries waste could sustain 5.9 million seabirds throughout the year, although this estimate refers to an absolute maximum (i.e. assuming a consumption rate of $100 \%$ ). If the levels of precision calcu- lated in the above hypothetical example applied to these studies, the estimated standard error could be around 30000 for the waters off Lower Saxony and around 3 million birds for the entire North Sea. Assuming a multiplicative error, the $95 \%$ confidence interval. would range between 22000 and 163000 birds in Lower Saxony and between 2.2 and 16.3 million birds in the North Sea.

Application of the Delta method also helps to identify the input variables with the largest contribution to the variance of the output variable (e.g Borchers et al. 1997). According to the precision estimates available here, the precision of the seabird estimates would benefit most by improvements in the estimation of total discards. Discard estimation from sampling programmes on board commercial vessels is currently an area of active research, with alternative design and model based estimators being tested (Stratoudakis et al. unpubl., M. McCracken, Department of Mathematics and Statistics, University of St. Andrews, Scotland, pers. comm.). Another input variable that probably contributes considerably to the variance of the overall estimate is consumption rate, a variable for which within-study variation is currently ignored. It is also possible that modelling the fate of offered fish as a function of fish length or number of seabirds present (see Garthe \& Hüppop 1998 for rationale) could improve the estimation of consumption rate.

In conclusion, although there is no doubt that seabirds feed extensively on fisheries waste, the estimates that have been provided up to date are biased and imprecise. Garthe \& Hüppop (1998) offer a way to deal with one of the major sources of bias, the singleitem release in experimental discarding. Here, I have shown how the application of the Delta method can provide approximate estimates of precision and confidence limits for the estimated number of seabirds. Despite its approximate nature, application of the Delta method may prevent point estimates of seabirds sustained on fisheries waste from being used out of context in debates related to conservation and fisheries management. It also helps to identify the research areas that would allow more precise estimates of seabirds to become available to decision makers.

Acknowledgements. I thank Rob Fryer and Mike Fine for comments on this manuscript. Most of my work on fisheries discards has been funded by the EU grants AIR GT93/2696 and FAIR GT95/6010.

\section{LITERATURE CITED}

Borchers DL, Buckland ST, Priede IG, Ahmadi S (1997) Improving the precision of the daily egg production method using generalised additive models. Can J Fish A.quat Sci 54:2727-2742 
Furness RW (1978) Energy requirements of seabird communities: a bioenergetics model. J Anim Ecol 47:39-53

Furness RW (1992) Implications of changes in net mesh size fishing effort and minimum landing size regulations in the North Sea for seabird populations. JNCC Report No. 133

Garthe S, Hüppop O (1994) Distribution of ship-following seabirds and their utilisation of discards in the North Sea. Mar Ecol Prog Ser 106:1-9

Garthe S, Hüppop O (1998) Possible biases in experiments evaluating the consumption of discards by seabirds in the North Sea. Mar Biol 131:735-741

Garthe S, Camphuysen CJ, Furness RW (1996) Amounts of discards by commercial fisheries and their significance as food for seabirds in the North Sea. Mar Ecol Prog Ser 136 : $1-11$

Hislop JRG. Harris MP, Smith JGM (1991) Variation in the calorific value and total energy content of the lesser sandeel (Ammodytes marinus) and other fish preyed on by seabirds. J Zool Lond 224:501-517
ICES (1994) Report of the study group on seabird/fish interactions. Copenhagen, 6-10/09/93. CM-ICES 1994/L:3

Oro D, Ruiz X (1997) Exploitation of trawler discards by breeding seabirds in the north-western Mediterranean: differences between the Ebro Delta and the Balearic Islands areas. ICES J Mar Sci 54:695-707

Prager MH, MacCall AD (1988) Sensitivities and variances of virtual population analysis as applied to the mackerel, Scomber japonicus. Can J Fish Aquat Sci 45:539-547

Seber GAF (1982) The estimation of animal abundance and related parameters, 2nd edn. Griffin $C$ and Co, London

Stratoudakis Y (1997) A study of fish discarded by Scottish demersal fishing vessels. PhD thesis, University of Aberdeen

Stratoudakis Y, Fryer RJ, Cook RM (1998) Discarding practices for commercial gadoids in the North Sea. Can J Fish Aquat Sci 55:1632-1644

Walter U, Becker PH (1997) Occurrence and consumption of seabirds scavenging on shrimp trawler discards in the Wadden Sea. ICES J Mar Sci 54:684-694 